\title{
A PROSPECTIVE STUDY OF VARIOUS AVAILABLE DIAGNOSTIC AND TREATMENT MODALITIES AND INTRAOPERATIVE FINDINGS OF NON-TRAUMATIC ACUTE ABDOMINAL CASES IN A TERTIARY CARE HOSPITAL OF CENTRAL INDIA
}

Rajiv Jain', Vikas Gupta ${ }^{2}$

${ }^{1}$ Associate Professor, Department of Surgery, Sri Aurobindo Medical College and PG Institute, Indore, Madhya Pradesh. ${ }^{2}$ Resident, Department of Surgery, Sri Aurobindo Medical College and PG Institute, Indore, Madhya Pradesh.

ABSTRACT
BACKGROUND
Acute abdominal pain is a common complaint of patients presenting at the Emergency Department. Patients presenting with acute
abdominal condition which often requires an immediate surgical intervention and is one of the commonly encountered emergencies
in the practice of General Surgery. Very often an accurate diagnosis cannot be made without surgery and many wonders are revealed
on opening the abdomen. So it is often the last court of appeal in investigating abdominal cases.

\section{MATERIALS AND METHODS}

This is a prospective study of 98 patients of non-traumatic acute abdominal cases conducted in a Tertiary Care Hospital of Central India. In our study, all routine blood investigations were carried out and relevant radiological investigations like abdomen x-ray, ultrasound whole abdomen was done in majority of patients and CT scan was done wherever needed. In our study 97 patients were managed surgically, while conservative management is done in only 1 patient.

\section{RESULTS}

Amongst the study of 98 patients x-ray, USG and CT were used as diagnostic modalities. Maximum cases were operated, while conservative management was done in one patient.

\section{CONCLUSION}

Our study is a sincere attempt to know the sensitivity of diagnostic modalities and to evaluate the treatment protocol in nontraumatic acute abdomen cases.

\section{KEYWORDS}

Acute Abdomen, Laparotomy, Abdomen X-Ray, Ultrasound Abdomen.

HOW TO CITE THIS ARTICLE: Jain R, Gupta V. A prospective study of various available diagnostic and treatment modalities and intraoperative findings of non-traumatic acute abdominal cases in a tertiary care hospital of Central India. J. Evolution Med. Dent. Sci. 2016;5(92):6829-6834, DOI: 10.14260/Jemds/2016/1545

\begin{abstract}
BACKGROUND
Acute abdominal pain is a common complaint of patients presenting at the Emergency Department.[1] Approximately, $10 \%$ of presentations at the Emergency Department are because of acute abdominal pain.[2] It can be caused by a variety of diseases ranging from mild and self-limiting to lifethreatening diseases. ${ }^{[2]}$ An early and accurate diagnosis results in more appropriate management and subsequently leads to better outcomes. The first step in the diagnostic pathway is clinical evaluation. In daily practice, a preliminary diagnosis should be made based on medical history, physical examination and in some cases laboratory parameters. After clinical assessment, the decision can be made to perform additional diagnostic investigations to increase certainty of the diagnosis. The use of additional imaging modalities such as plain radiography, ultrasound and Computed Tomography (CT) has increased over the years. Only a few decades ago,
\end{abstract}

Financial or Other, Competing Interest: None.

Submission 13-10-2016, Peer Review 06-11-2016,

Acceptance 12-11-2016, Published 17-11-2016.

Corresponding Author:

Dr. Rajiv Jain,

27, Anand Bagichi, Agrawal Nagar,

Indore-452001,

Madhya Pradesh.

E-mail:drrajivjain16@yahoo.com

DOI: $10.14260 /$ jemds/2016/1545

(c) $($ ) $\$$ when imaging was not widely available and its diagnostic accuracy was low, patients would immediately proceed to the operating theatre. However, many causes can be treated conservatively and do not need diagnostic laparoscopy and laparotomy.[3]

The terms "acute abdomen" and "abdominal emergency," which are constantly applied to such cases signify the need for prompt diagnosis and early treatment. Patients presenting with acute abdominal condition, which often requires an immediate surgical intervention and is one of the commonly encountered emergencies in the practice of General Surgery.[4,5] Very often an accurate diagnosis cannot be made without surgery and many wonders are revealed on opening the abdomen. So it is often the last court of appeal in investigating abdominal cases. [6] The "aim of this study" was to study various diagnostic modalities, their effectiveness and treatment modalities in patients presenting with "NonTraumatic Acute Abdomen in Central India."

\section{MATERIALS AND METHODS}

This is a prospective study of 98 patients of non-traumatic acute abdominal cases conducted in a Tertiary Care Hospital of Central India. In our study, all routine blood investigations were carried out and relevant radiological investigations like abdomen x-ray, ultrasound whole abdomen was done in majority of patients and CT scan was done wherever needed. 
In our study, 97 patients were managed surgically while conservative management was done in only 1 patient.

\section{Study Design}

- Sample Size - 98 patients were included in the study.

- Study Duration - January 2015 to July 2016.

\section{Inclusion Criteria}

1. Patients with history of acute onset of pain in abdomen.

2. Positive findings in USG and $x$-ray abdomen erect.

3. Patients and/or his/her legally acceptable representative willing to provide voluntary written informed consent for participation in the study.

\section{Exclusion Criteria}

1. All the OPD cases [cases who would not get admitted].

2. Patients presented with acute abdomen of traumatic origin.

3. Pregnant women and children (less than 15 years) presented with acute abdomen.

4. Patients and/or his/her legally acceptable representative not willing to provide voluntary written informed consent for participation in the study.

\section{RESULTS}

$(\mathrm{N}=98)$

\begin{tabular}{|c|c|c|}
\hline Investigations Done & No. & \% \\
\hline Ultrasound whole abdomen & 98 & 100.0 \\
\hline Abdomen x-ray & 51 & 52.0 \\
\hline CT scan whole abdomen & 19 & 19.4 \\
\hline Diagnostic laparoscopy & 02 & 2.04 \\
\hline Table 1. Distribution of Patients according to \\
Investigations Done \\
\hline
\end{tabular}

In our study Ultrasound whole abdomen was done in all the patients $98(100.0 \%)$, while abdomen $\mathrm{x}$-ray was done in 51 (52.0\%) patients and Computerised Tomography scan whole abdomen was done wherever indicated; hence, it was done in only $19(19.4 \%)$ patients and diagnostic laparoscopy was done in $02(2.04 \%)$ of the total patients studied.

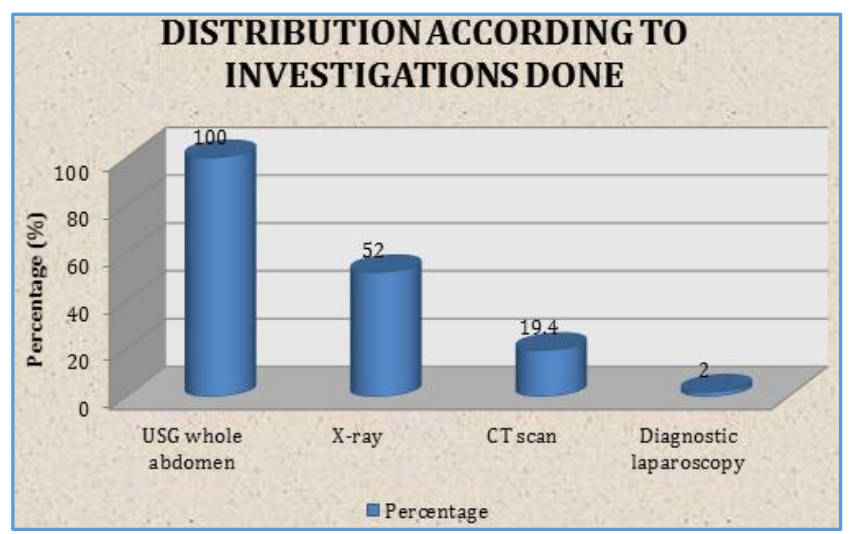

Figure 1. Bar Diagram showing Distribution of Patients according to Investigations Done [Ref. Table No. 1]
$(\mathrm{N}=51)$

\begin{tabular}{|c|c|c|c|}
\hline \multirow{2}{*}{$\begin{array}{c}\text { X-Ray } \\
\text { Findings }\end{array}$} & \multicolumn{2}{|c|}{ Intraoperative Findings } & \multirow{2}{*}{$\begin{array}{c}\text { Grand } \\
\text { Total }\end{array}$} \\
\hline & Negative & Positive & \\
\hline Negative & 1 & 2 & 3 \\
\hline Positive & 8 & 40 & 48 \\
\hline Total & 9 & 42 & 51 \\
\hline
\end{tabular}

The above table shows the association of abdomen x-ray findings with intraoperative findings.

The Sensitivity, Specificity, Positive Predictive Value and Negative Predictive Value of Abdomen $x$-ray is given below

$$
\begin{array}{ll}
\text { Sensitivity: } & 95.2 \% \\
\text { Specificity: } & 11.11 \%
\end{array}
$$

\section{Positive Predictive}

Value: $\quad 83.3 \%$

Negative Predictive

Value: $\quad 33.33 \%$

$(\mathrm{N}=98)$

\begin{tabular}{|c|c|c|c|}
\hline \multirow{2}{*}{$\begin{array}{c}\text { Ultrasound Whole } \\
\text { Abdomen Findings }\end{array}$} & \multicolumn{2}{|c|}{$\begin{array}{c}\text { Intraoperative } \\
\text { Findings }\end{array}$} & \multirow{2}{*}{$\begin{array}{c}\text { Grand } \\
\text { Total }\end{array}$} \\
\cline { 2 - 3 } & Negative & Positive & \\
\hline Negative & 1 & 4 & 5 \\
\hline Positive & 34 & 59 & 93 \\
\hline Total & $\mathbf{3 5}$ & $\mathbf{6 3}$ & $\mathbf{9 8}$ \\
\hline
\end{tabular}

Table 3. Association of Ultrasound Whole Abdomen Findings with Intraoperative Findings

The above table shows the association of Ultrasound whole abdomen findings with intraoperative findings.

The Sensitivity, Specificity, Positive Predictive Value and Negative Predictive Value of Ultrasound whole Abdomen is given below

$\begin{array}{ll}\text { Sensitivity: } & 93.65 \% \\ \text { Specificity: } & 2.85 \%\end{array}$

\section{Positive Predictive}

Value:

$63.4 \%$

Negative Predictive

Value: $\quad 20.0 \%$

$(\mathrm{N}=19)$
\begin{tabular}{|c|c|c|c|}
\hline $\begin{array}{c}\text { CT Scan Whole } \\
\text { Abdomen } \\
\text { Findings }\end{array}$ & \multicolumn{2}{|c|}{$\begin{array}{c}\text { Intraoperative } \\
\text { Findings }\end{array}$} & \multirow{2}{*}{$\begin{array}{c}\text { Grand } \\
\text { Total }\end{array}$} \\
\cline { 2 - 3 } & Negative & Positive & \\
\hline Negative & 2 & 2 & 4 \\
\hline Positive & 6 & 9 & 15 \\
\hline Total & $\mathbf{8}$ & $\mathbf{1 1}$ & $\mathbf{1 9}$ \\
\hline
\end{tabular}

Table 4. Association of Computerised Tomography Scan Whole Abdomen Findings with Intraoperative Findings

The above table shows the association of Computerised Tomography scan findings with intraoperative findings. 
The Sensitivity, Specificity, Positive Predictive Value and Negative Predictive Value of Computerised Tomography Scan is given below

\section{Sensitivity: $\quad 81.81 \%$ \\ Specificity: $\quad 25 \%$ \\ Positive Predictive \\ Value: \\ $60.0 \%$}

\section{Negative Predictive}

Value:

$50.0 \%$

$(\mathrm{N}=98)$

\begin{tabular}{|c|c|c|}
\hline Type of Management & No. & $\mathbf{\%}$ \\
\hline Open surgery & 88 & 92.6 \\
\hline Laparoscopic surgery & 09 & 9.2 \\
\hline Conservative & 01 & 1.0 \\
\hline Total & $\mathbf{9 8}$ & $\mathbf{1 0 0 . 0}$ \\
\hline Table 5. Distribution of Patients according to Type of \\
Management \\
\hline
\end{tabular}

As per above table out of 98 patients open surgical management was done in 88 (92.6\%), while laparoscopic surgery was done in $9(9.2 \%)$ and conservative management was done in only $1(1.0 \%)$ of the total patients studied.

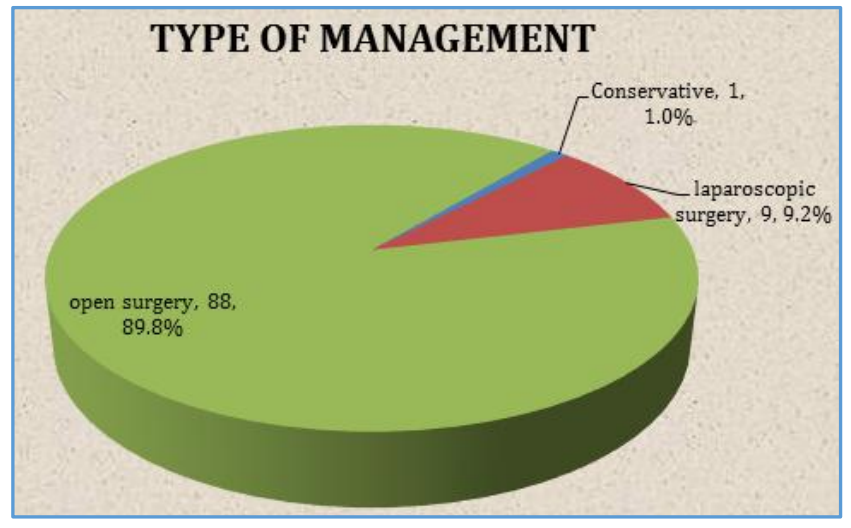

Figure 2. Pie Diagram showing Type of Management [Ref. Table No. 5]

\begin{tabular}{|c|c|c|}
\hline Site of Perforation & No. & $\%$ \\
\hline Ileal & 18 & 46.2 \\
\hline Gastric & 14 & 35.9 \\
\hline Appendicular & 2 & 5.1 \\
\hline Jejunal & 2 & 5.1 \\
\hline Caecal & 2 & 5.1 \\
\hline Sigmoid & 1 & 2.6 \\
\hline Total & 39 & 100.0 \\
\hline \multicolumn{3}{|c|}{$\begin{array}{l}\text { Table 6. Distribution of Cases of Perforation Peritonitis } \\
\text { on the Basis of Site of Perforation }\end{array}$} \\
\hline
\end{tabular}

In our study, perforation peritonitis was seen in 39 patients. Of these 39 patients, perforation which formed the major cause of acute abdomen in the study was found to be ileal in 18 (46.2\%) followed by gastric in 14 (35.9\%).

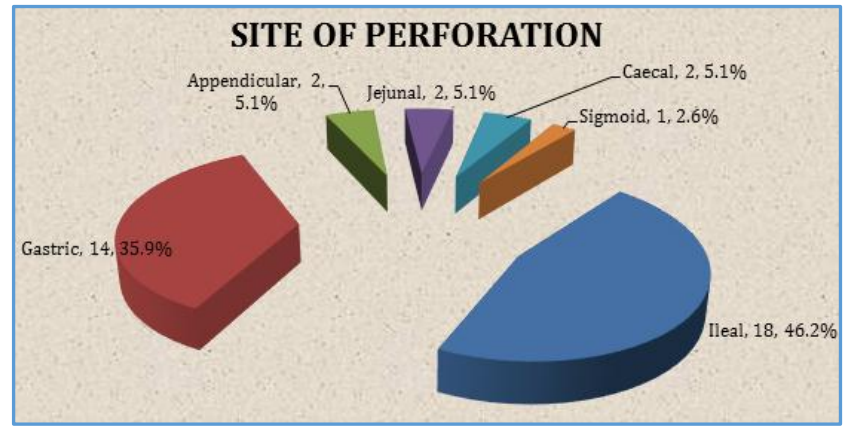

Figure 3. Pie Diagram showing Sites of Perforation [Ref. Table No. 6]

$(\mathrm{N}=3)$
\begin{tabular}{|c|c|c|}
\hline Ruptured Liver Abscess & No. & $\mathbf{\%}$ \\
\hline Surgical & 2 & 66.7 \\
\hline Laparoscopic drainage & 1 & 33.3 \\
\hline Total & $\mathbf{3}$ & $\mathbf{1 0 0 . 0}$ \\
\hline Table 7. Treatment of Ruptured Liver Abscess \\
\hline
\end{tabular}

There were 3 cases of ruptured liver abscess. Of these 2 (66.7\%) were managed surgically, while laparoscopic drainage was done in 1 (33.3\%) of the total patients studied.

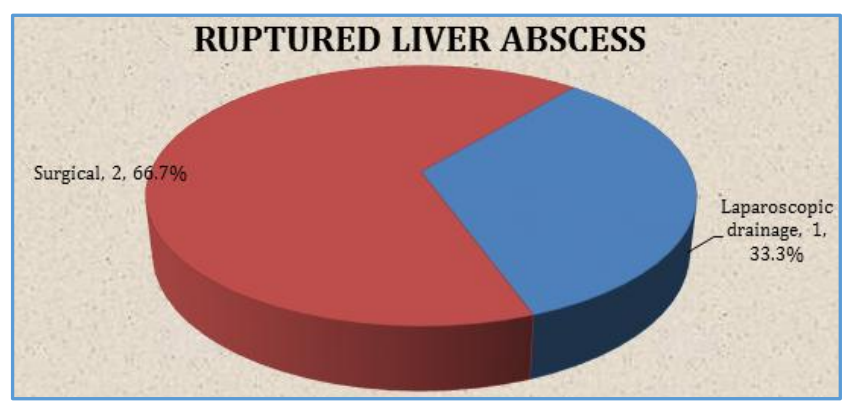

Figure 4. Pie Diagram showing Management of Ruptured Liver Abscess [Ref. Table No. 7]

$(\mathrm{N}=13)$

\begin{tabular}{|c|c|c|}
\hline Aetiology & No. & $\%$ \\
\hline Adhesions/bands & 9 & 69.2 \\
\hline Volvulus & 2 & 15.4 \\
\hline Foreign body & 1 & 7.7 \\
\hline Internal hernias & 1 & 7.7 \\
\hline Total & 13 & 100.0 \\
\hline
\end{tabular}

Intestinal obstruction was seen in 13 cases in our series. Of these, most common aetiology was found to be adhesions/bands in 9 (69.2\%) followed by volvulus in 2 (one caecal and one sigmoid) (15.4\%), foreign body and internal hernias in only $1(7.7 \%)$ of the total patients studied. 


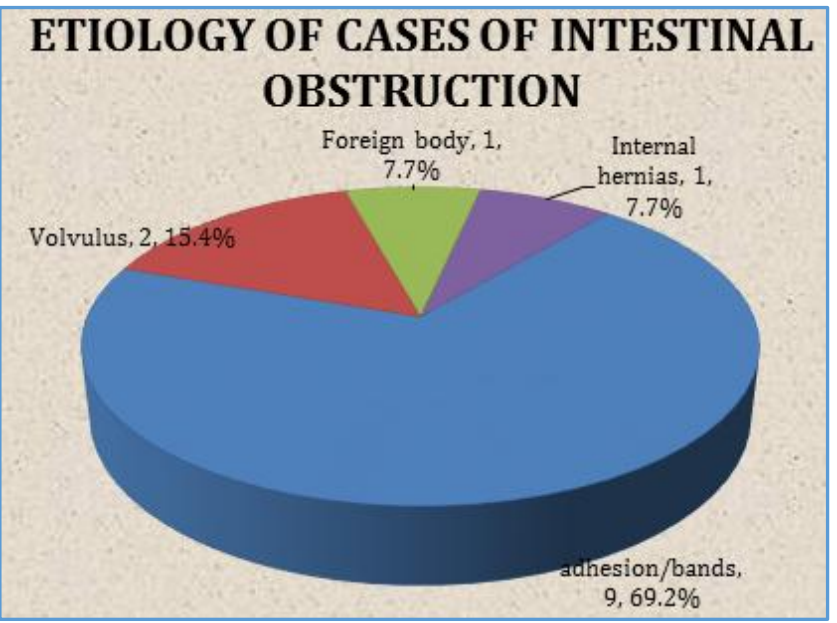

Figure 5. Pie Diagram showing Aetiology of Cases of Intestinal Obstruction [Ref. Table No. 8]

$(\mathrm{N}=14)$

\begin{tabular}{|c|c|c|}
\hline Management & No. & $\%$ \\
\hline Open surgical management & 12 & 85.7 \\
\hline Laparoscopic surgical management & 1 & 7.1 \\
\hline Conservative management & 1 & 7.1 \\
\hline Total & $\mathbf{1 4}$ & $\mathbf{1 0 0 . 0}$ \\
\hline Table 9. Management of Cases of Intestinal Obstruction \\
\hline
\end{tabular}

Of the 14 cases of intestinal obstruction observed in our study, $12(85.7 \%)$ were managed by open surgery and 1 (7.1\%) by laparoscopic surgery, while $1(7.1 \%)$ was managed conservatively.

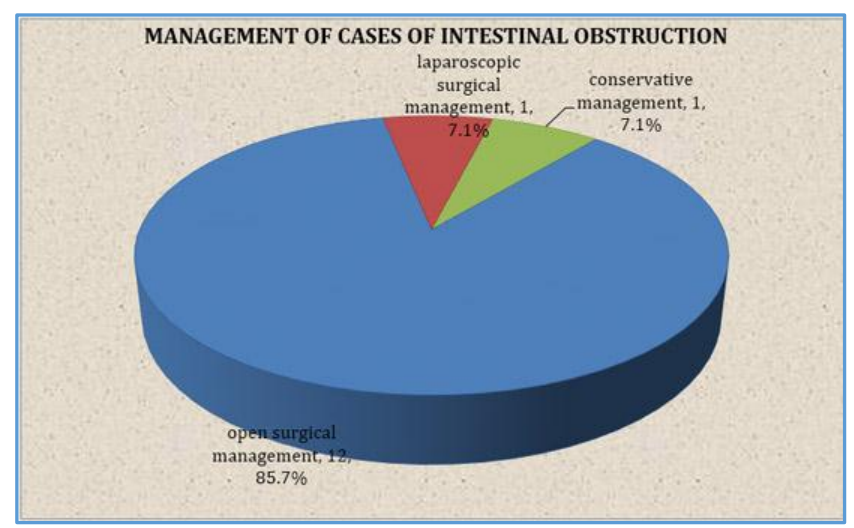

Figure 6. Pie Diagram showing Management of Cases of Intestinal Obstruction [Ref. Table No. 9]

$$
(\mathrm{N}=9)
$$

\begin{tabular}{|c|c|c|}
\hline Diagnosis & No. & $\%$ \\
\hline Appendicitis & 3 & 33.3 \\
\hline Unclear diagnosis & 2 & 22.2 \\
\hline Gall bladder pathology & 2 & 22.2 \\
\hline Intestinal obstruction & 1 & 11.1 \\
\hline Liver abscess & 1 & 11.1 \\
\hline
\end{tabular}

Among 9 patients managed by laparoscopic surgery, laparoscopic appendicectomy was done in $3(33.3 \%)$ patients of appendicitis, while in patients with unclear diagnosis (diagnostic laparoscopy with appendicectomy) in 2 (22.2\%) of the total patients studied.

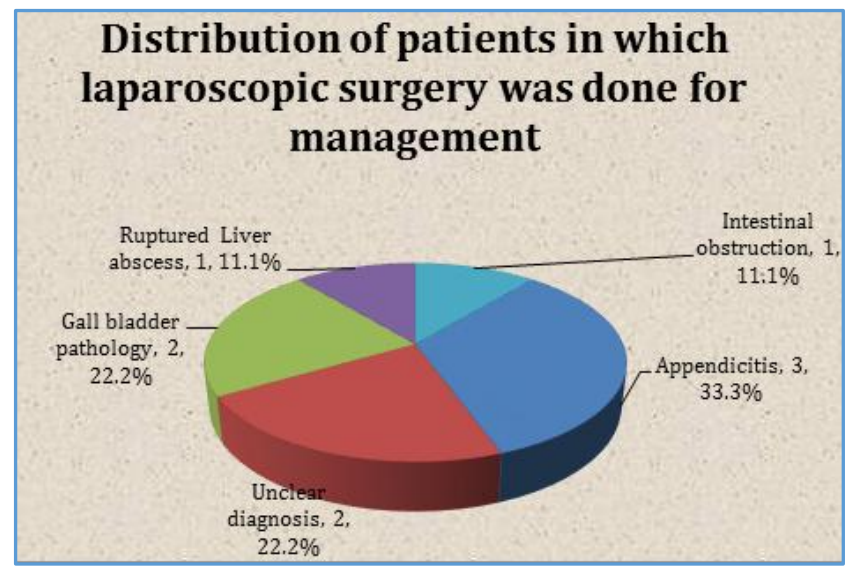

Figure 7. Pie Diagram showing Distribution of Patients in which Laparoscopic Surgery was Done [Ref. Table No. 10]

$(\mathrm{N}=37)$

\begin{tabular}{|c|c|c|}
\hline Position of Appendix (Intra-0p) & No. & $\mathbf{\%}$ \\
\hline Retro-caecal & 30 & 81.1 \\
\hline Pelvic & 4 & 10.8 \\
\hline Pre-ileal & 2 & 5.4 \\
\hline Post-ileal & 1 & 2.7 \\
\hline $\begin{array}{c}\text { Table 11. Distribution of the Different Positions of } \\
\text { Appendix Found during Appendicectomy }\end{array}$ \\
\hline
\end{tabular}

Among 37 cases of this study in which appendicectomy was done, on the basis of intra-operative findings, as per above table, the commonest position of appendix was retrocaecal in $30(81.1 \%)$, pelvic in $4(10.8 \%)$, pre-ileal in $2(5.4 \%)$ and postileal in $1(2.7 \%)$ of the total patients studied.

\section{Distribution of the different positions of appendix found during appendicectomy}

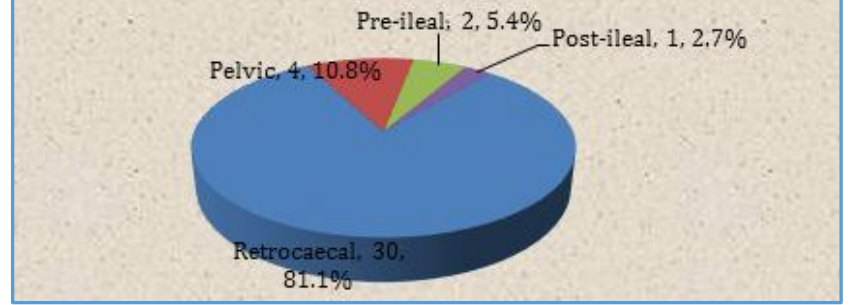

Figure 8. Pie Diagram showing Distribution of Different Positions of Appendix found during Appendicectomy

[Ref. Table No. 11]

\section{DISCUSSION}

Acute abdominal pain constitutes a significant percentage of emergency admissions worldwide and comprises a largest group (non-traumatic) of people presenting as general surgery emergency. The pattern of disease may vary according to age, sex, geography, class and genetic factors. The purpose of this study was to evaluate the various diagnostic modalities, their role in making decision regarding surgery ${ }^{[7]}$ and to know various treatment modalities in patients presenting with non- 
traumatic acute abdomen in a tertiary care hospital of Central India.

\section{Investigations}

In our study, abdomen x-ray is the investigation with highest sensitivity (95.2\%) followed by ultrasound abdomen (93.65\%). In a similar study done by K. Gupta et al[8] in 2005, where ultrasound is the investigation of choice with highest sensitivity (98.3\%) followed by abdomen x-ray (70.9\%). Hence, results in our study are different with the findings of the study done by K. Gupta et al.

\section{Type of Management}

In the present study, majority of patients were treated by open surgical method (92.6\%) and some patients by laparoscopic surgery (9.2\%). In a similar study done by Ferdinando Agresta et al[9] in 2004 where majority of patients were treated by laparoscopic surgery (94.1\%), while less by open surgical method (5.8\%). Hence, results in our study regarding type of management are different from the study done by the author.

\section{Site of Perforation}

In our study, the most commonest site of perforation peritonitis is ileal (46.2\%) followed by gastric (35.9\%). In a similar study done by Rajender Singh Jhobta et al[10] in 2006, where the most commonest site was duodenal (57\%) followed by ileal (15\%) and study done by Memon et al[11] in 2008, the commonest site was gastric (14.6\%) followed by ileal (5.9\%). Hence, findings in our study regarding site of perforation is different as compared with the findings of other authors.

\section{Treatment of Ruptured Liver Abscess}

In our study, majority of patients of ruptured liver abscess were treated by open surgical method (66.7\%). In a similar study done by Jin Fu Tu et al[12] in 2011, majority of patients of ruptured liver abscess were treated by open surgical method (58.06\%). Hence, findings in our study is similar to findings of Jin Fu Tu et al.

\section{Aetiology and Management of Intestinal Obstruction}

In our study, the common cause of intestinal obstruction is adhesions/bands (69.2\%) followed by volvulus (15.4\%). In a similar study done by Patrick G. Jackson et al[13] in 2011, the common cause is adhesions/bands (60\%) followed by neoplasm (20\%). Hence, our study on aetiology of intestinal obstruction matches with the study done by the author.

In our study, majority of cases of intestinal obstruction were managed by open surgical method (85.7\%) and few cases by laparoscopic surgical management $(7.1 \%)$ and remaining by conservative management (7.1\%). In a similar study done by Adhikari Souvik et al[14] in 2010, majority of cases were managed by open surgical method (78.4\%), while conservative management was done (14.17\%) and in a similar study done by Mohamed AY et al[15] in 1997 majority of patients were managed by open surgical method (73\%) and conservative management $(27 \%)$. So our findings match with the findings of other studies and the standard treatment of acute intestinal obstruction is by surgery only.

\section{Patients Treated by Laparoscopy}

In present study out of nine patients in which laparoscopic surgery was done for management in majority of patients laparoscopic appendicectomy was done (33.3\%) for acute appendicitis, diagnostic laparoscopy with appendicectomy (22.2\%), laparoscopic cholecystectomy (22.2\%) for gall bladder pathology, while laparoscopic adhesiolysis (11.1\%) of intestinal obstruction. In a similar study done by Edvaldo Fahel et al[16] in 1999, where laparoscopic appendicectomy $(44.15 \%)$ was done for acute appendicitis followed by laparoscopic cholecystectomy (21.4\%) for gall bladder pathology. Thus, we conclude that in an era of laparoscopic surgery, it has been the "gold standard" for many elective procedures and has been used in abdominal emergencies for diagnosis as well as for treatment purposes. Different positions of appendix found during appendicectomy in the present study, the commonest position of appendix found during appendicectomy is retrocaecal $(81.1 \%)$ followed by pelvic $(10.1 \%)$. In a similar study done by Patel KG et al,[17] in 2013 the commonest position of appendix found during appendicectomy is retrocaecal (62\%) followed by pelvic (13\%). Hence, our study on different positions of appendix found during appendicectomy matches with the study done by author.

\section{CONCLUSION}

The increasing incidence of cases of non-traumatic acute abdomen is a diagnostic dilemma for the surgeons and warrants early recognition and prompt treatment to avoid major morbidity and mortality. Acute abdomen is often a surgical emergency and a challenge to any surgeon. Abdominal pain is a common presenting complaint in the emergency department and surgeons must consider multiple diagnoses, especially in those cases that require immediate intervention in order to limit morbidity and mortality. Rigorous approach to diagnosis is mandatory. It is extremely important for surgeons to develop the skill of identifying patients with an "acute abdomen" requiring immediate surgical intervention. Our study is a sincere attempt to know the sensitivity of diagnostic modalities, treatment protocol in non-traumatic acute abdomen cases presenting in tertiary care centre in Central India.

\section{REFERENCES}

1. Kamin RA, Nowicki TA, Courtney DS, et al. Pearls and pitfalls in the emergency department evaluation of abdominal pain. Emerg Med Clin North Am 2003;21(1):6172.

2. Lameris W, van Randen A, van Es HW, van Es Wouter H, et al. Imaging strategies for detection of urgent conditions in patients with acute abdominal pain: diagnostic accuracy study. BMJ 2009;338:b2431.

3. Hastings RS, Powers RD. Abdominal pain in the ED: a 35 year retrospective. Am J Emerg Med 2011;29(7):711-6.

4. Kotiso B, Abdurahman Z. Pattern of acute abdomen in adult patients in tikuranbessa teaching hospital, Addis Ababa, Ethiopia. East and Central African Journal of Surgery 2006;12(1):47-52.

5. Tsegaye S, Osman M, Bekele A. Surgically treated acute abdomen at Gondar university hospital, Ethiopia. East and Central African Journal of Surgery 2007;12(1):53-7. 
6. Ray S, Patel M, Parmar H. Management of acute abdomen. Study of 110 cases. IAIM 2016;3(2):18-24.

7. Aviral, Chana RS, Ahmad I. Role of Ultrasonography in evaluation of children with acute abdomen in the emergency set up at JNMC Aligarh, India. J Indian Assoc Pediatr Surg 2005;10(1):41-3.

8. Gupta K, Bhandari RK, Chander R. Comparative study of plain abdomen and ultrasound in non-traumatic acute abdomen. Indian J Radiol \& Imaging 2005;15(1):109-15.

9. Agresta F, De Simone P, Bedin N. The laparoscopic approach in abdominal emergencies: a single-center 10year experience. Journal of the Society of Laparoendoscopic Surgeons 2004;8(1):25-30.

10. Jhobta RS, Attri AK, Kaushik R, et al. Spectrum of perforation peritonitis in India-review of 504 consecutive cases. World Journal of Emergency Surgery 2006;1:26.

11. Memon AA, Bhutto AA, Shaikh GS, et al. Spectrum of diseases in patients with non traumatic acute abdomen. JLUMHS 2008;7(3):180-3.

12. Jin-Fu Tu, Xiu-Fang $\mathrm{H}, \mathrm{Ru}-\mathrm{Ying} \mathrm{Hu}$, et al. Comparison of laparoscopic and open surgery for pyogenic liver abscess with biliary pathology. World J Gastroenterol 2011; 17(38):4339-343.
13. Jackson PG, Raiji M. Evaluation and Management of Intestinal Obstruction. Am Fam Physician 2011;83(2):15965.

14. Souvik A, Hossein MZ, Amitabha D, et al. Etiology and outcome of acute intestinal obstruction: a review of 367 patients in Eastern India. Saudi J Gastroenterol 2010;16(4):285-7.

15. Mohamed AY, al-Ghaithi A, Langevin JM, et al. Causes and management of intestinal obstruction in a Saudi Arabian hospital. J R Coll Surg Edinb 1997;42(1):21-3.

16. Fahel E, Amaral PC, Filho EM, et al. Non-traumatic acute abdomen: videolaparoscopic approach. JSLS 1999;3(3): 187-92.

17. Patel KG, Thekdi PI, Nathwani P, et al. A comparative study of different anatomical position, clinical presentation and USG findings with operative findings in patients of appendicitis. Int J Res Med Sci 2013;1(4):349-53. 